\title{
Application of Augmented Simplex Centroid Design for Optimization of HPLC Mobile Phase for Estimation of Curcumin and Piperine
}

\author{
Jahnavi Naik', Sonal Desai ${ }^{1, *}$, Vinodkumar Ramani² \\ 1'Department of Quality Assurance, S.S.R. College of Pharmacy, S.S.R. Campus, Silvassa, UT of Dadra \& Nagar Haveli, INDIA. \\ 2Department of Pharmaceutics, Bhagwan Mahavir College of Pharmacy, BMEF Campus, VIP Road, Surat, Gujarat, INDIA.
}

\begin{abstract}
Background: Optimization of mobile phase for high performance liquid chromatography (HPLC) is an exigent task where one factor at a time (OFAT) approach is not preferable as it is time consuming specially for multifaceted samples. The paper describes Augmented Simplex Centroid Design (ASCD) for optimization of ternary mobile phase system for reversed phase HPLC method. The proposed design was utilized for development of mobile phase composition for simultaneous estimation of curcumin and piperine present in dietary supplement. Materials and Methods: Separation was achieved on Sunniest $\mathrm{C}_{18}$ column (150 mm x $4.6 \mathrm{~mm}, 5 \mu$ ). Elution was carried out using in isocratic mode using mobile phase, 0.1 \% OPA: ACN: THF (52.7: 37.3: 10.0, v/v/v) at flow rate of $1 \mathrm{ml} / \mathrm{min}$. Sample injection volume was $20 \mu \mathrm{l}$. Detection was carried out at $361 \mathrm{~nm}$ and run time was 20 min. Results: The proposed method was linear over concentration range of $1-6 \mu \mathrm{g} / \mathrm{ml}$ for both curcumin and piperine with the regression coefficient 0.9954 and 0.9575 , respectively. The limit of detection of the proposed HPLC method for curcumin and piperine were found to be $0.0621 \mu \mathrm{g} / \mathrm{ml}$ and $0.0633 \mu \mathrm{g} / \mathrm{ml}$, respectively. The limit of quantification of the proposed HPLC method for curcumin and piperine were found to be $0.1863 \mu \mathrm{g} / \mathrm{ml}$ and $0.1899 \mu \mathrm{g} / \mathrm{ml}$, respectively. The percentage recovery of both curcumin and piperine were found to be in the range of $96.5366-115.6833 \%$. The proposed method was precise and robust. Conclusion: The method was successfully applied for standardization of dietary supplement containing curcumin and piperine.
\end{abstract}

Key words: Augmented simplex centroid design, Curcumin, HPLC, Piperine.

\section{INTRODUCTION}

HPLC method development for herbal samples is crucial because of the presence of a large number of similar components. It involves finding optimum composition of mobile phase containing two or more solvents. Design of Experiments (DoE) or experimental design, involves controlled tests for evaluation of effect of the factors on response variables. ${ }^{1}$ Factorial designs (FD) and central composite design (CCD) have limited applications as with increased number of factors, number of experiments increases. ${ }^{2}$ Mixture design is used when the independent factors are proportions of different components mixed together to evaluate their effect on a particular response. The independent factors in a mixture designs are components of a mixture and the measured response is assumed to depend only on the proportions of the components in the mixture and not on the amount of the mixture. Mixture designs are mainly of four types: simplex lattice design, simplex centroid design, extreme vertex design and simplex axial design. Simplex lattice design is used when the number of components is small. In this design, simplex points are considered, i.e. the points which are on the three sides of the triangle and the three vertices (Figure 1a).
Submission Date: 10-10-2020; Revision Date: 17-02-2021; Accepted Date: 24-08-2021

DOI: 10.5530/ijper.55.4.216 Correspondence: Dr. Sonal Desai, Department of Quality Assurance, S.S.R. College of Pharmacy, S.S.R. Campus, Sayli Road, Silvassa-396 230, Gujarat, INDIA. Phone: +91-0260-2681105, Email - sdesai6381@gmail. com

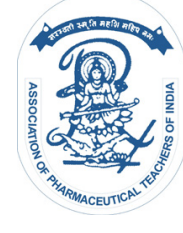

www.ijper.org 


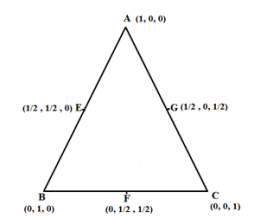

(a) Simplex lattice design

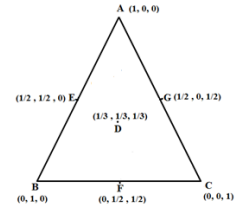

(b) Simplex centroid design

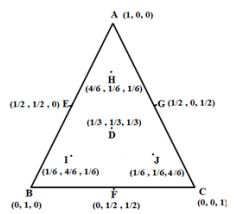

(c) Augmented simplex centroid
Figure 1: Diagrammatic representation of various mixture designs.

Simplex centroid design is used for the identification of important components in the mixture which contains a large number of components. In this design, the centre point of the triangle is also considered, i.e. the vertices, the midpoints of each side of the triangle and the centre point of the whole triangle (Figure 1b). Extreme vertex design which is also referred to as constrained mixture design which is used when constraints are added. It requires restricted ranges on one or more of the factors and covers small portions within the simplex. Here minimum and maximum value for each component is fixed. Simplex axial design or augmented simplex centroid design is the design which consists of the points of vertices, the midpoints of each side of the triangle, the centre point of the main triangle and axial points (Figure 1c). An axial point is a blend where the component proportions are the mean of the centre point and a vertex. Axial points help to extract information about the inner portion of the response surface. ${ }^{3}$ Various analytical methods are available for the identification and quantification of both curcumin and piperine. Curcumin was estimated along with other curcuminoids by HPLC. ${ }^{4,5}$ Simultaneous estimation of curcumin and quercetin by UV and HPLC was reported. ${ }^{6}$ Reversed phase HPLC methods were described for estimation of curcumin and silibinin ${ }^{7}$ and for curcumin and cinnamaldehyde. ${ }^{8}$ HPLC methods are also available in literature for the analysis of piperine alone ${ }^{9,10}$ Validated UV spectrophotometric method was reported for simultaneous estimation of piperine, quercetin and curcumin. ${ }^{11}$ Curcumin and piperine was quantitated in crude powder mixture and Ayurvedic formulation by HPTLC. ${ }^{12}$ Ramaswamy et al. presented a validated RP-UFLC method for simultaneous estimation of curcumin and piperine. ${ }^{13}$ The proposed method was sensitive but curcumin and piperine were closely eluting as the difference of mean retention times of curcumin and piperine is $0.8 \mathrm{~min}$. Another HPLC method for the simultaneous estimation of curcumin and piperine in Eudragit E 100 nanoparticles was described. ${ }^{14}$ The working range of the method was 10 to
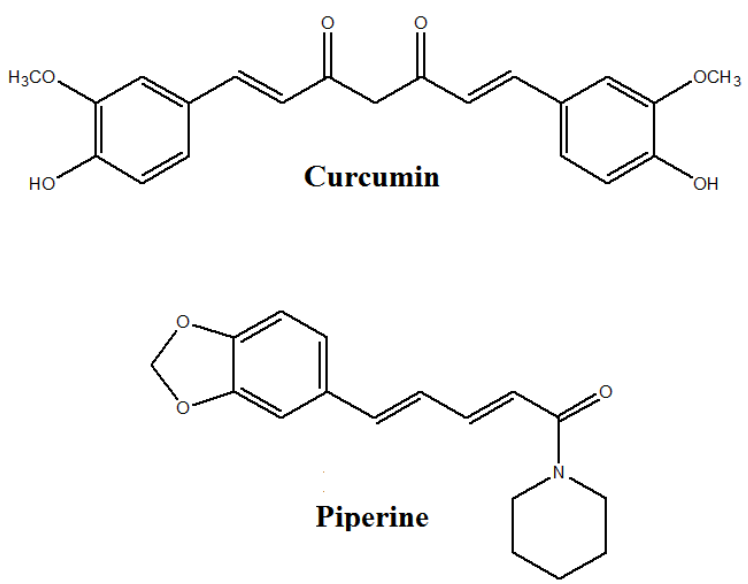

Figure 2: Structures of curcumin and piperine.

$150 \mu \mathrm{g} / \mathrm{ml}$. HPLC-MS/MS was developed for estimation of curcumin and piperine in human plasma. ${ }^{15}$

Though there are few HPLC methods available, there is a need to develop a sensitive HPLC method which can provide optimum resolution between curcumin and piperine. Use of mixture design to optimize mobile phase composition during HPLC method development allows the evaluation of the effect of proportions of the solvents on chromatographic parameters. To the best of our knowledge, no method is available for the simultaneous estimation of curcumin and piperine using mixture design. This paper describes optimization of HPLC mobile phase using augmented simplex centroid design for the simultaneous estimation of curcumin and piperine present in dietary supplement with special emphasis on retention times of both markers and resolution.

\section{MATERIALS AND METHODS}

\section{Chemicals and reagents}

The reference standards of curcumin and piperine were purchased from Sigma Aldrich, Mumbai, India. The dietary supplement containing Curcuma longa and Piper nigrum were procured from Search Creations, Ujjain, India. All the solvents used were of HPLC grade and were purchased from Fischer Scientific India Pvt. Ltd., Mumbai, India.

\section{Instrument}

A Cyber Lab HPLC chromatograph (LC 100, USA) equipped with a solvent delivery system (LC - 100), UV detector (UV - 100), data system (DS - 100) and rhedodyne injector (7725i) with $20 \mu$ loop was used for the analysis. All the data were analyzed by Workstation Software (WS - 100). Mixture design was performed by 
Design - Expert trial software version 10.0.6 (Stat - ease Inc., Minneapolis).Statistical calculations for the method validation were performed using Microsoft Excel software (Microsoft Corporation, USA).

\section{Method development}

As curcumin and piperine were soluble in methanol, reversed phase technique was chosen. Initially the separation was carried out using Sunchrome C18 $(250 \mathrm{~mm}$ $\times 4.6 \mathrm{~mm}$ I.D., $5.0 \mu \mathrm{m})$ column. Various organic solvents like methanol or acetonitrile was tried in different ratio with aqueous solvents such as water, $0.1 \%$ orthophosphoric acid, $0.1 \%$ formic acid or trifluoroaceatic acid in isocratic mode as mobile phase. Effects of these solvents on responses such as retention time $(\mathrm{Rt})$, resolution $(\mathrm{Rs})$, number of plates $(\mathrm{N})$ and tailing factor $(\mathrm{T})$ were evaluated. Due to poor resolution between both compounds and high retention, it was decided to perform the separation on Sunniest C18 $(150 \mathrm{~mm} \times 4.6 \mathrm{~mm}$ I.D., $5.0 \mu \mathrm{m})$ column. Ternary mobile phase conatining $0.1 \%$ orthophosphoric acid (OPA), acetonitrile (ACN) and tetrahydrofuran (THF) produced better results as compared to other mobile phases. The flow rate of mobile phase was kept at 1 $\mathrm{ml} / \mathrm{min}$. Sample injection volume was $20 \mu \mathrm{l}$. Detection wavelength was selected based on isobestic point of Curcumin and piperine. The separation was performed at room temperature.

\section{Preparation of standard solution}

Accurately weighed $0.01 \mathrm{gm}$ of standard curcumin and piperine were transferred in two different $100 \mathrm{ml}$ volumetric flasks. The volume was made up to the mark with HPLC grade methanol. The solutions were sonicated for $10 \mathrm{~min}$.

\section{Preparation of test solution}

Test solution was prepared using commercial capsule formulation of dietary supplement containing Curcuma longa and Piper nigrum. Accurately weighed $1 \mathrm{gm}$ of capsule powder was taken and treated with $20 \mathrm{ml}$ of petroleum ether. The supernatant fluid was decanted and marc was allowed to dry. Accurately measured $20 \mathrm{ml}$ of ethyl acetate was added and sonicated for $10 \mathrm{~min}$. The solution was then filtered and ethyl acetate extract was allowed to evaporate for dryness. Accurately weighed $0.01 \mathrm{gm}$ of the ethyl acetate extract was taken in $100 \mathrm{ml}$ volumetric flask. The volume was made upto mark with HPLC grade methanol. The solution was sonicated for $10 \mathrm{~min}$.

\section{Preparation of mobile phase}

Accurate volume of $0.1 \mathrm{ml}$ of orthophosphoric acid was transferred in $100 \mathrm{ml}$ volumetric flask and diluted up to the mark with HPLC grade water. The required volume of this solution was pipetted out and mixed with required volume of acetonitrile and tetrahydrofuran. This mixture of solvent was sonicated for $20 \mathrm{~min}$.

\section{Initial method optimization}

Initial mobile phase optimization was carried out based on one factor at a time approach. Various mobile phases were tried at different compositions. Mobile phase using $0.1 \%$ orthophosphoric acid (OPA), acetonitrile (ACN) and tetrahydrofuran (THF) in ratio of $57: 33: 10, \mathrm{v} / \mathrm{v} / \mathrm{v}$ gave optimum resolution and retention time. This mobile phase was further optimized using augmented simplex centroid design.

\section{Software aided mobile phase optimization}

A simplex centroid design with axial points in a pseudo component representation was generated from the pure mobile phase components which were $0.1 \%$ OPA, ACN and THF. The pseudo components are given by $A=57$ : 33: $10, B=43: 47: 10$ and $C=43: 33: 24$ in the proportions of $0.1 \%$ OPA, ACN and THF, respectively.

In the present study, the synergic and antagonistic effects of mobile phase mixture on the chromatographic responses were studied using statistical methods. Design Expert ${ }^{\circledR}$ (Trial Version 10.0.6) was used for analysing the results of the experimental design. $\{3,2\}$ simplex lattice design augmented with the axial points was used. This design offered 10 points as given in Figure 1c. Ten mixtures of various proportions of $0.1 \%$ OPA, ACN and THF were prepared by using augmented simplex centroid design as shown in Table 1 and Table 2 . The proportions of all the solvents in each mixture were sum to $100 \%$, which means a volume of $100 \mathrm{ml}$.

\begin{tabular}{|c|c|c|c|c|c|c|}
\hline \multirow[t]{2}{*}{ Points } & \multicolumn{3}{|c|}{$\begin{array}{c}\text { Composition } \\
\text { of Pseudo } \\
\text { components }\end{array}$} & \multicolumn{3}{|c|}{ Composition of mobile phase } \\
\hline & 1 & 2 & 3 & $0.1 \%$ OPA (ml) & $\mathrm{ACN}(\mathrm{ml})$ & THF (ml) \\
\hline A & 1 & 0 & 0 & 57 & 33 & 10 \\
\hline B & 0 & 1 & 0 & 43 & 47 & 10 \\
\hline C & 0 & 0 & 1 & 43 & 33 & 24 \\
\hline D & $1 / 3$ & $1 / 3$ & $1 / 3$ & 47.66 & 37.67 & 14.67 \\
\hline E & $1 / 2$ & $1 / 2$ & 0 & 50 & 40 & 10 \\
\hline $\mathrm{F}$ & 0 & $1 / 2$ & $1 / 2$ & 43 & 40 & 17 \\
\hline G & $1 / 2$ & 0 & $1 / 2$ & 50 & 33 & 17 \\
\hline $\mathrm{H}$ & $4 / 6$ & $1 / 6$ & $1 / 6$ & 52.33 & 35.33 & 12.34 \\
\hline 1 & $1 / 6$ & $4 / 6$ & $1 / 6$ & 45.33 & 42.33 & 12.34 \\
\hline $\mathrm{J}$ & $1 / 6$ & $1 / 6$ & $4 / 6$ & 45.33 & 35.33 & 19.34 \\
\hline
\end{tabular}




\begin{tabular}{l} 
Table 2: Results of ASCD with the three responses retention time of curcumin, retention time of piperine and \\
resolution. \\
\cline { 1 - 6 } Run
\end{tabular}

\section{Model Validation}

All the trials using different mobile phase composition as stated in the above Table 2 were carried out. The effect of different mixtures of the solvents on chromatographic responses such as retention time of piperine, retention time of curcumin and resolution were evaluated. The results obtained were analyzed using Design Expert software. From the optimized mobile phase, best mobile phase in the composition was used for model validation. The predicted responses and the results obtained were compared.

\section{Chromatographic conditions}

Separation was achieved on Sunniest $C_{18}$ column $(150 \mathrm{~mm} \times 4.6 \mathrm{~mm}, 5 \mu)$. Elution was carried out in isocratic mode using mobile phase, $0.1 \%$ OPA: ACN: THF (52.7: 37.3: 10.0, v/v/v) at flow rate of $1 \mathrm{ml} / \mathrm{min}$. Injection volume was kept at $20 \mu \mathrm{l}$. Detection was carried out at $361 \mathrm{~nm}$ and run time was $20 \mathrm{~min}$.

\section{Method validation}

The developed and optimized method was validated as per ICH guidelines for the various parameters such as specificity, system suitability, limit of detection, limit of quantification, linearity and range, accuracy, precision and robustness. ${ }^{16}$ For the evaluation of specificity; blank, standard solutions of curcumin and piperine and test solution were injected in triplicate. Any interference from the blank solution, sample constituents and mobile phase to the peaks was checked. System suitability parameters such as repeatability of the peak area, number of theoretical plates and tailing factor were evaluated by applying six injections of standards solution containing each of $3 \mu \mathrm{g} / \mathrm{ml}$ of curcumin and piperine. The limit of detection and limit of quantification were calculated by standard deviation method. Standard solutions of curcumin and piperine were prepared in the range of $0.1-0.6 \mu \mathrm{g} / \mathrm{ml}$. Each solution was injected in triplicate and the area was noted. Calibration curve of area versus concentration was plotted and LOD and LOQ of curcumin and piperine were calculated. The linearity of the developed method was estimated using standard solutions of six different concentrations in the range of $1-6 \mu \mathrm{g} / \mathrm{ml}$ for both curcumin and piperine in triplicate. Graph of the average area versus concentration was plotted and the regression coefficient $\left(\mathrm{R}^{2}\right)$ was calculated for both curcumin and piperine. The accuracy of the method was determined by standard addition method by individually calculating the percentage recovery of curcumin and piperine. The study was carried out at three different levels $(50 \%$, $100 \%$ and $150 \%$ ) and in triplicates. The known amount of test solution containing $1 \mu \mathrm{g} / \mathrm{ml}$ each of curcumin and piperine was spiked into the standard solution of each of curcumin and pipeirne $(1.5 \mu \mathrm{g} / \mathrm{ml}, 3.0 \mu \mathrm{g} / \mathrm{ml}$ and $4.5 \mu \mathrm{g} / \mathrm{ml}$ ). The individual area of curcumin and piperine were recorded at each level and the $\%$ recovery was calculated. The precision studies were carried out as interday and intraday studies at three different concentration levels for both curcumin and piperine. The concentrations of both curcumin and piperine at $50 \%, 100 \%$ and $150 \%$ levels were $1.5 \mu \mathrm{g} / \mathrm{ml}, 3.0 \mu \mathrm{g} / \mathrm{ml}$ and $4.5 \mu \mathrm{g} / \mathrm{ml}$, respectively. The solution containing curcumin and piperine was injected in triplicate at each level. Intraday precision studies were carried on same day but at different time interval. The interday 
studies were carried on different consecutive days. The area of curcumin and piperine at each concentration level were recorded. The \% RSD was calculated for curcumin and piperine. The robustness of the method was evaluated by slightly varying the method parameters such as wavelength $(360 \mathrm{~nm}$ and $362 \mathrm{~nm})$, flow rate $(0.9 \mathrm{ml} / \mathrm{min}$ and $1.1 \mathrm{ml} / \mathrm{min})$ and mobile phase composition (53.7: 37.3: 09, v/v/v and 51.7: 37.3: 11, v/v/v). The standard solutions containing curcumin and piperine $(3 \mu \mathrm{g} / \mathrm{ml}$ each) were injected six times and test solution $(3 \mu \mathrm{g} / \mathrm{ml})$ was injected twice. The $\% \mathrm{w} / \mathrm{w}$ and $\%$ RSD was calculated for both curcumin and piperine.

\section{Quantification of curcumin and piperine in dietary supplement by HPLC}

The test solution of dietary supplement was prepared and injected in triplicate. The percentage $\mathrm{w} / \mathrm{w}$ of curcumin and piperine were calculated.

\section{RESULTS AND DISCUSSION}

Isosbestic point, $361 \mathrm{~nm}$ was selected as the detection wavelength for the simultaneous estimation curcumin and piperine in the dietary supplements. For the development of optimum mobile phase compositions, various trials were carried out using different reversed phase solvents in varying proportions. Various trials using different compositions and solvents were carried out for the optimization of mobile phase such as methanol, water, orthophosphoric acid, acetonitrile, tetrahydrofuran, formic acid, trifluoroacetic acid, buffer orthophosphoric acid. $0.1 \%$ OPA, ACN and THF in the ratio 57: 33: 10, v/v/v gave better resolution. Mobile phase was further optimized using augmented simplex centroid design. For the software aided method optimization, three responses were studied, i.e., retention time of piperine, retention time of curcumin and resolution. The 3D surface plot (Figure 3), contour plots (Figure 4) and predicted vs. actual plots (Figure 5) for all the three responses were studied.

\section{Retention time of curcumin}

For response retention time of curcumin, the best suited model was special quartic model. The $\mathrm{F}$ value for model was found to be 1277.50 which indicated that the model was significant. The value of $R^{2}$ was found to be 0.9999 indicating that there was an excellent fit of special quartic model to the mixture design results. The values of predicted $R^{2}$ and that of adjusted $R^{2}$ were found to be 0.9232 and 0.9991 , respectively. The difference between the values of predicted $R^{2}$ and adjusted $R^{2}$ was less than 0.2 indicating that there is reasonable agreement between them. The value of

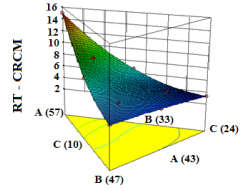

(d) Response Retention Time of Curcumin

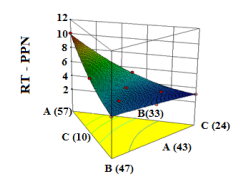

(e) Response Retention Time of Piperine

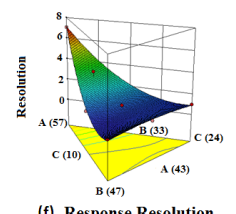

(f) Response Resolutio
Figure 3: 3D surface plots for (d) retention time of curcumin (e) retention time of piperine (f) resolution.

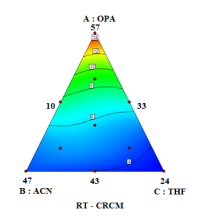

(g) Response Retention Time of Curcumin

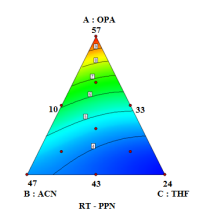

(h) Response Retention Time of Piperine

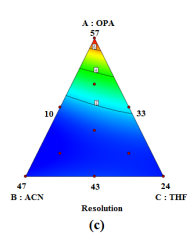

(i) Response Resolutio
Figure 4: Contour plots for $(\mathrm{g})$ retention time of curcumin (h) retention time of piperine (i) resolution.

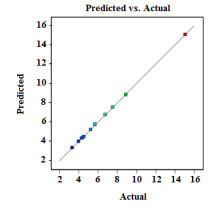

(j) Retention Time of Curcumin

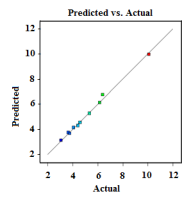

(k) Response Retention Time of Piperine

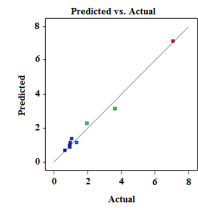

(I) Response Resolution
Figure 5: Predicted versus actual plots for (j) retention time of curcumin (k) retention time of piperine (I) resolution.

adequate precision was found to be 120.629 (a ratio greater than 4 is desirable) indicating that there was an adequate signal (Table 3). The final equation in terms of L_Pseudo components with the significance coefficients is given in Table 3 . From equation given in Table 3 , it can be seen that $\beta 1>\beta 2>\beta 3$ ( $\beta O P A>$ $\beta A C N>\beta T H F)$ Hence, it was concluded that high proportion of OPA produced highest retention time of curcumin. Furthermore, since $\beta 23$ ( $\beta A C N$ THF) was positive which indicated that mixing ACN and THF resulted in high retention time of curcumin. On the other hand, significant negative $\beta 12$ ( $\beta O P A \quad A C N)$ and $\beta 13$ ( $\beta O P A$ THF) coefficients indicated low retention time obtained with binary mixture of OPA with ACN and THF. That means coefficient $\beta 23$ ( $\beta A C N$ THF) had synergistic effect whereas $\beta 12$ ( $\beta \mathrm{OPA} A C N$ ) and $\beta 13$ ( $\beta \mathrm{OPA}$ THF) had antagonist effect for response retention time of curcumin. Figure $3 \mathrm{~d}$ and Figure $4 \mathrm{~g}$ shows the 3D surface plot and the contour plot for response retention time of curcumin, respectively. Based on normal probability plots of the residuals, it was observed that the experi- 
mental points were reasonably aligned indicating the normal distribution of data for the response retention time of curcumin (Figure 5j).

\section{Retention time of piperine}

For response retention time of piperine, the best suited model was special cubic model. The $F$ value for model was found to be 105.61 which indicated that the model was significant. The value of $R^{2}$ was found to be 0.9953 indicating that there was a reasonable fit of special cubic model to the mixture design results. The values of predicted $R^{2}$ and that of adjusted $R^{2}$ were found to be 0.8317 and 0.9859 , respectively. The difference between the values of predicted $R^{2}$ and adjusted $R^{2}$ was less than 0.2 indicating that there was reasonable agreement between them. The value of adequate precision was found to be 33.785 (a ratio greater than 4 is desirable) indicating that there was an adequate signal (Table 3). The final equation in terms of L_Pseudo components with the significance coefficients is given in Table 3. From equation given in Table 3, it can be seen that $\beta 1>\beta 2>\beta 3$ ( $\beta$ OPA> $\beta A C N>\beta T H F)$ Hence, it was concluded that high proportion of OPA produced highest retention time of piperine. Furthermore, since $\beta 23$ ( $\beta$ ACN THF) was positive which indicated that mixing ACN and THF resulted in high retention time of piperine. On the other hand, significant negative $\beta 12$ ( $\beta O P A$ ACN) and $\beta 13$ ( $\beta O P A$ THF) coefficients indicated low retention time obtained with binary mixture of OPA with ACN and THF. That means coefficient $\beta 23$ ( $\beta A C N$ THF) had synergistic effect whereas $\beta 12$ ( $\beta$ OPA ACN) and $\beta 13$ ( $\beta \mathrm{OPA}$ THF) had antagonist effect for response retention time of piperine. Figure $3 \mathrm{e}$ and Figure $4 \mathrm{~h}$ shows the 3D surface plot and the contour plot for response retention time of piperine, respectively. Based on normal probability plots of the residuals, it was observed that the experimental points were reasonably aligned indicating the normal distribution of data for the response retention time of piperine (Figure 5k).

\section{Resolution}

For response resolution, the best suited model was quadratic model. The F value for model was found to be 52.29 which indicated that the model was significant. The value of $R^{2}$ was found to be 0.9849 indicating that there was a reasonable fit of quadratic model to the mixture design results. The values of predicted $\mathrm{R}^{2}$ and that of adjusted $R^{2}$ were found to be 0.7756 and 0.9661 , respectively. The difference between the values of predicted $R^{2}$ and adjusted $R^{2}$ was less than 0.2 indicating that there was reasonable agreement between them. The value of adequate precision was found to be 22.818 (a ratio greater than 4 is desirable) indicating that there was an adequate signal (Table 3 ). The final equation in terms of L_Pseudo components with the significance coefficients is given in Table 3. From equation given in Table 3 , it can be seen that $\beta 1>\beta 2>\beta 3$ ( $\beta O P A>\beta A C N>$ $\beta$ THF) Hence, it was concluded that high proportion of OPA produced highest resolution. Furthermore, since $\beta 23$ ( $\beta A C N$ THF) is positive which indicated that mixing ACN and THF resulted in high value of resolution. On the other hand, significant negative $\beta 12$ ( $\beta \mathrm{OPA}$ $\mathrm{ACN}$ ) and $\beta 13$ ( $\beta \mathrm{OPA}$ THF) coefficients indicated low retention time obtained with binary mixture of OPA with ACN and THF. That means coefficient $\beta 23$ ( $\beta A C N$ THF) had synergistic effect whereas $\beta 12$ ( $\beta$ OPA $A C N)$ and $\beta 13$ ( $\beta$ OPA THF) had antagonist effect for response resolution. Figure $3 \mathrm{f}$ and Figure $4 \mathrm{i}$ shows the $3 \mathrm{D}$ surface plot and the contour plot for response resolution, respectively. Based on normal probability plots of the residuals, it was observed that the experimental points were reasonably aligned indicating the normal distribution of data for the response retention time of resolution (Figure 51).

\section{Model optimization}

The optimization of the mixture proportions was used to identify the combination of the input variables setting that jointly optimize desired responses. Using Design Expert ${ }^{\circledR}$ (Version 10.0.6) software, optimum ratio of the mobile phase obtained was $0.1 \%$ OPA, ACN and THF in the ratio 52.7: 37.3: 10.0, v/v/v.

\section{Model validation}

From the optimization plot, the best mobile phase combination was $0.1 \%$ OPA, ACN and THF in the ratio 52.7: $37.3: 10.0, \mathrm{v} / \mathrm{v} / \mathrm{v}$, respectively. The predicted responses for this mobile phase were retention time of piperine at $7.38 \mathrm{~min}$, retention time of curcumin at $9.95 \mathrm{~min}$ and resolution of 3 with desirability 1.000 . In order to validate the model, the trial was conducted with the optimum mobile phase obtained.

\section{Method validation}

The proposed HPLC method was found to be specific as there was no interference found from the solvent, mobile phase or any other components present in the test solution. (Figure 6 and 7). The number of theoretical plates is a measure of column efficiency which was found to be more than 2000 for both curcumin and piperine. The tailing factor for both the peaks were found to be less than 2 . The $\%$ RSD for all the parameters 


\begin{tabular}{|c|c|c|c|c|c|c|c|c|c|}
\hline \multirow[t]{2}{*}{ Response } & \multicolumn{9}{|c|}{ Statistical Analysis for the responses } \\
\hline & Model & $\mathbf{R}^{2}$ & $\begin{array}{l}\text { Adj } \\
R^{2}\end{array}$ & $\begin{array}{l}\text { Pred } \\
\mathbf{R}^{2}\end{array}$ & $\begin{array}{c}\text { Adeq } \\
\text { Precisio-n }\end{array}$ & $\begin{array}{c}\text { Sum of } \\
\text { square } \\
\text { (AB) }\end{array}$ & $\begin{array}{c}\text { Sum of } \\
\text { square } \\
\text { (AC) }\end{array}$ & $\begin{array}{c}\text { Sum of } \\
\text { square } \\
\text { (BC) }\end{array}$ & $\% \mathrm{CV}$ \\
\hline $\begin{array}{l}\text { Retention time of } \\
\text { Curcumin }\end{array}$ & $\begin{array}{l}\text { Special } \\
\text { Quartic }\end{array}$ & 0.9999 & 0.9991 & 0.9232 & 120.629 & 3.10 & 3.96 & 0.016 & 1.57 \\
\hline $\begin{array}{l}\text { Retention time of } \\
\text { piperine }\end{array}$ & $\begin{array}{l}\text { Special } \\
\text { Cubic }\end{array}$ & 0.9953 & 0.9859 & 0.8317 & 33.785 & 0.60 & 1.12 & 0.0081 & 4.71 \\
\hline Resolution & Quadratic & 0.9849 & 0.9661 & 0.7756 & 22.818 & 5.64 & 2.44 & 0.052 & 18.71 \\
\hline \multicolumn{10}{|c|}{ Regression equation of the fitted model } \\
\hline $\begin{array}{l}\text { Retention time of } \\
\text { curcumin }\end{array}$ & \multicolumn{9}{|c|}{$Y=+15.06^{*} A+4.33^{*} B+3.34^{*} C-8.61^{*} A B-9.74^{*} A C+0.61^{*} B C-53.34^{*} A^{2} B C+40.01^{*} A B 2 C+25.21^{*} A B C^{2}$} \\
\hline $\begin{array}{l}\text { Retention time of } \\
\text { piperine }\end{array}$ & \multicolumn{9}{|c|}{$Y=+9.97^{*} A+4.12^{*} B+3 \cdot 11^{*} C-3.76^{*} A^{*} B-5 \cdot 14^{*} A^{*} C+0.44^{*} B^{*} C-7 \cdot 37^{*} A^{*} B^{*} C$} \\
\hline Resolution & \multicolumn{9}{|c|}{$Y=+7.16^{*} A+0.88^{*} B+0.87^{*} C-10.56^{*} A B-6.94^{*} A C+1.01^{*} B C$} \\
\hline
\end{tabular}

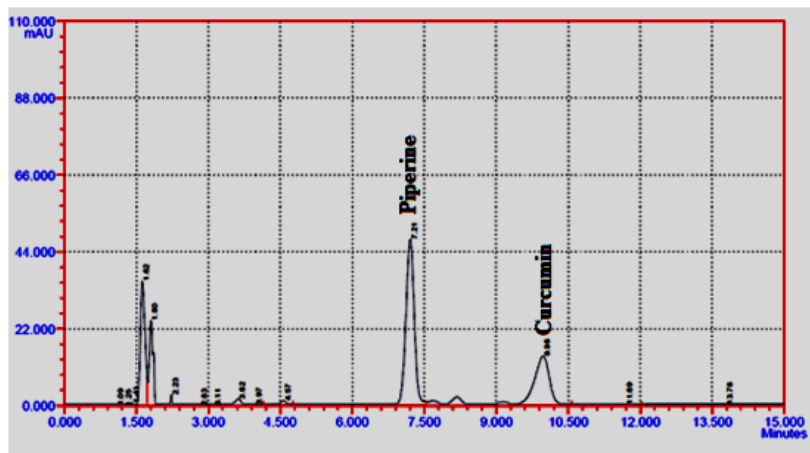

Figure 6: Chromatogram of standard curcumin and piperine.

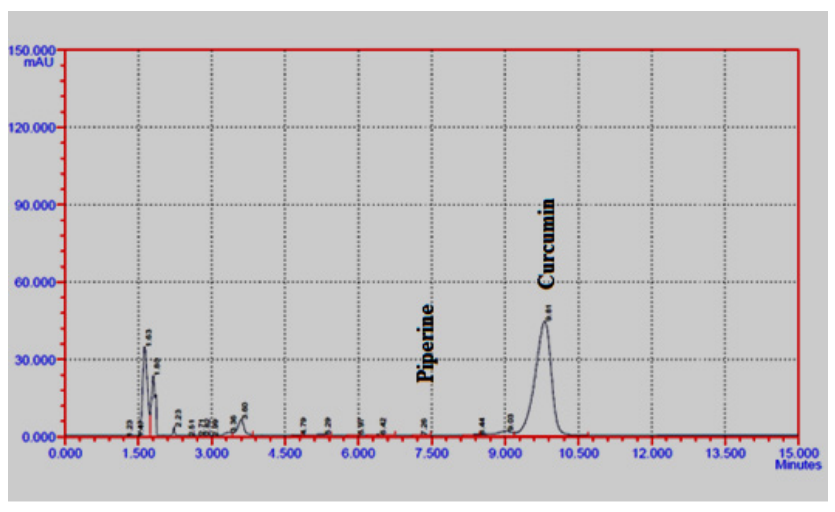

Figure 7: Chromatogram of ethyl acetate extract of sample of dietary supplement.

were found to be less than $2 \%$. The limit of detection of the proposed HPLC method for curcumin and piperine were found to be $0.0621 \mu \mathrm{g} / \mathrm{ml}$ and 0.0633 $\mu \mathrm{g} / \mathrm{ml}$, respectively. The limit of quantification of the proposed HPLC method for curcumin and piperine

\begin{tabular}{|c|c|c|c|}
\hline $\begin{array}{l}\text { Sr. } \\
\text { No. }\end{array}$ & $\begin{array}{l}\text { Validation } \\
\text { parameters }\end{array}$ & $\begin{array}{l}\text { Curcumin } \\
\text { Rt } 9.98 \mathrm{~min}\end{array}$ & $\begin{array}{c}\text { Piperine } \\
\text { Rt } 7.21 \mathrm{~min}\end{array}$ \\
\hline 1 & $\begin{array}{c}\text { System suitability } \\
\text { test } \\
\text { Number of } \\
\text { theoretical plates } \\
\text { Peak Asymmetry } \\
\text { Resolution } \\
\text { Repeatability of } \\
\text { peak area }\end{array}$ & $\begin{array}{c}>4000 \\
<2.0 \\
3.0 \\
\% \text { RSD }<1.0\end{array}$ & $\begin{array}{c}>6000 \\
<2.0 \\
3.0 \\
\% \text { RSD }<1.0\end{array}$ \\
\hline 2 & LOD & $0.0621 \mu \mathrm{g} / \mathrm{ml}$ & $0.0633 \mu \mathrm{g} / \mathrm{ml}$ \\
\hline 3 & LOQ & $0.1863 \mu \mathrm{g} / \mathrm{ml}$ & $0.1899 \mu \mathrm{g} / \mathrm{ml}$ \\
\hline 4 & $\begin{array}{l}\text { Linearity and } \\
\text { range }\end{array}$ & $1-6 \mu \mathrm{g} / \mathrm{ml}$ & $1-6 \mu \mathrm{g} / \mathrm{ml}$ \\
\hline 5 & Accuracy & $102.38-115.68 \%$ & $96.53-108.83 \%$ \\
\hline 6 & Intraday precision & $\begin{array}{c}\text { \% RSD 0.6199- } \\
1.6573\end{array}$ & $\begin{array}{c}\% \text { RSD } \\
0.1099-1.6327\end{array}$ \\
\hline 7 & Interday precision & $\begin{array}{c}\% \text { RSD } 0.5940- \\
1.2077\end{array}$ & $\begin{array}{c}\text { \% RSD } 0.7453- \\
1.6407\end{array}$ \\
\hline 8 & Robustness & $\%$ RSD $<2.0$ & $\% \mathrm{RSD}<2.0$ \\
\hline
\end{tabular}

were found to be $0.1863 \mu \mathrm{g} / \mathrm{ml}$ and $0.1899 \mu \mathrm{g} / \mathrm{ml}$, respectively. The proposed method showed linearity over the concentration range of $1-6 \mu \mathrm{g} / \mathrm{ml}$ for both curcumin and piperine with the regression coefficients 0.9954 and 0.9575 , respectively. The equations of regression line are $y=3226.6 x+523.11$ and $y=1860 x+7183.1$ for curcumin and piperine, respectively. The percentage recovery of both curcumin and piperine were found to be in the range of $96.5366-115.6833 \%$. Interday and intraday precision studies were carried out to check the degree of scatterness of the results obtained by the 
proposed method. The \% RSD for both curcumin and piperine were found to be less than 2 for both interday and intraday precision studies. Thus, the developed method was found to be precise. In robustness studies, the $\%$ RSD for both curcumin and piperine were found to be less than 2 in the case of area of standard solutions of curcumin and piperine. The $\% \mathrm{w} / \mathrm{w}$ of both curcumin and piperine were found to be in between $75.63-78.66 \%$ and $93.00-100.45 \%$, respectively for both altered and unaltered conditions. Table 4 describes summary of results of method validation.

\section{Quantification of curcumin and piperine in dietary supplement by HPLC}

It was found that the $\% \mathrm{~W} / \mathrm{W}$ of curcumin and $\% \mathrm{~W} / \mathrm{W}$ of piperine in selected dietary supplement were found to be $47.5752 \%$ and $0.0688 \%$, respectively.

\section{CONCLUSION}

ASCD was utilized for optimization of HPLC mobile phase for quantitative determination of curcumin and piperine in dietary supplement. Effects of the mixture of OPA, ACN and THF on the chromatographic responses such as retention time of piperine, retention time of curcumin and resolution were evaluated. ANOVA studies revealed that proportion of OPA had significant effect on responses retention of curcumin, retention of piperine and resolution. The values of the adjusted R2 were greater than 0.9 for all responses which also confirmed that all selected models were highly significant. The design was sufficient to predict optimum proportion of OPA, ACN and THF as mobile phase for simultaneous estimation of curcumin and piperine.

\section{CONFLICT OF INTEREST}

The authors declare no conflict of interest.

\section{ABBREVIATIONS}

ASCD: Augmented Simplex Centroid Design; ACN: Acetonitrile; ANOVA: Analysis of Variance; DoE: Design of Experiments; CCD: Central Composite Design; LOD: Limit of Detection; FD: Factorial designs; LOQ: Limit of Quantification; OFAT: One Factor At a Time; OPA: Ortho Phosphoric Acid; HPLC: High Performance Liquid Chromatography; ICH: International Conferences on Harmonization;
RSD: Relative Standard Deviation; SD: Standard Deviation; THF: Tetra Hydro Furan.

\section{REFERENCES}

1. Telford JK. A brief introduction to design of experiments. Johns Hopkins Apl Technical Digest. 2007;27(3):224-32.

2. Asghar A, Abdul Raman AA, Daud WM. A comparison of central composite design and Taguchi method for optimizing Fenton process. ScientificWorldJournal. 2014;2014:869120. doi: 10.1155/2014/869120. PMID 25258741.

3. Cano CB, Felsner ML, Bruns RE, Matos JR, Almeida-Muradian LB. Optimization of mobile phase for separation of carbohydrates in honey by high performance liquid chromatography using a mixture design. J Braz Chem Soc. 2006;17(3):588-93. doi: 10.1590/S0103-50532006000300024.

4. Jayaprakasha GK, Jagan Mohan Rao L, Sakariah KK. Improved HPLC method for the determination of curcumin, demethoxycurcumin, and bisdemethoxycurcumin. J Agric Food Chem. 2002;50(13):3668-72. doi: 10.1021/jf025506a, PMID 12059141.

5. Wichitnithad W, Jongaroonngamsang N, Pummangura S, Rojsitthisak P. A simple isocratic HPLC method for the simultaneous determination of curcuminoids in commercial turmeric extracts. Phytochem Anal. 2009;20(4):314-9. doi: 10.1002/pca.1129, PMID 19402187.

6. Salunkhe VR, Patil SJ. UV spectrophotometric and HPLC method development of quercetin and curcumin in polyherbal churna and its validation. Int J Pharm Phytopharmacol Res. 2014;4(1):8-12.

7. Moorthi C, Kathiresan K. Simultaneous estimation of curcumin and silibinin using validated RP-HPLC-PDA method and its application in pharmaceutical nanoformulation. Int J Pharm Pharm Sci. 2013;5(3):475-8.

8. Gavhad G, Sirsath V, Chaware V, Biyani K. Development and validation of RP-HPLC method for the simultaneous determination of cinnamaldehyde and curcumin in pharmaceutical formulation of lozenges. Int J Pharm Sci Res. 2015;4:311-16.

9. Verzele M, Qureshi S. HPLC determination of piperine in pepper and in pepper extracts. Chromatographia. 1980;13(4):241-3. doi: 10.1007/BF02261881.

10. Santosh MK, Shaila D, Rajyalakshmi I, Rao IS. RP-HPLC method for determination of piperine from Piper longum Linn. e-journal of Chemistry. Vol. 2; 2005.

11. Aneja G, Dave $U$, Vadodaria K. Simultaneous estimation of piperine, quercetin and curcumin in a mixture using UV-Visible spectrophotometer and method validation. IJTA. 2012;8:14-7.

12. Vyas N, Gamit K, Khan MY, Panchal S, Pundarikakshudu K. Simultaneous estimation of curcumin and piperine in their crude powder mixture and ayurvedic formulation using high performance thin layer chromatography. Int J Res Pharm Biomed Sci. 2011;2(01):231-6.

13. Ramaswamy S, Kuppuswamy G, Dwarampudi P, Kadiyala M, Menta L, Kannan E. Development and validation of simultaneous estimation method for curcumin and piperine by RP-UFLC. Pak J Pharm Sci. 2014;27(4):901-6. PMID 25015458.

14. Moorthi C, Senthil Kumar CS, Mohan S, Krishnan K, Kathiresan K. Application of validated RP-HPLC-PDA method for the simultaneous estimation of curcumin and piperine in Eudragit E 100 nanoparticles. J Pharm Res. 2013;7(3):224-9. doi: 10.1016/j.jopr.2013.03.006.

15. Wang XM, Zhang QZ, Yang J, Zhu R, Zhang J, Cai LJ, Peng WX. Validated HPLC-MS/MS method for simultaneous determination of curcumin and piperine in human plasma. Trop J Pharm Res. 2012;11(4):621-9. doi: 10.4314/tjpr.v11i4.13.

16. $\mathrm{ICH}$ Expert working group. ICH guideline Q2(R1) Validation of analytical methods definitions and terminology. International conference on Harmonisation; 2005. 


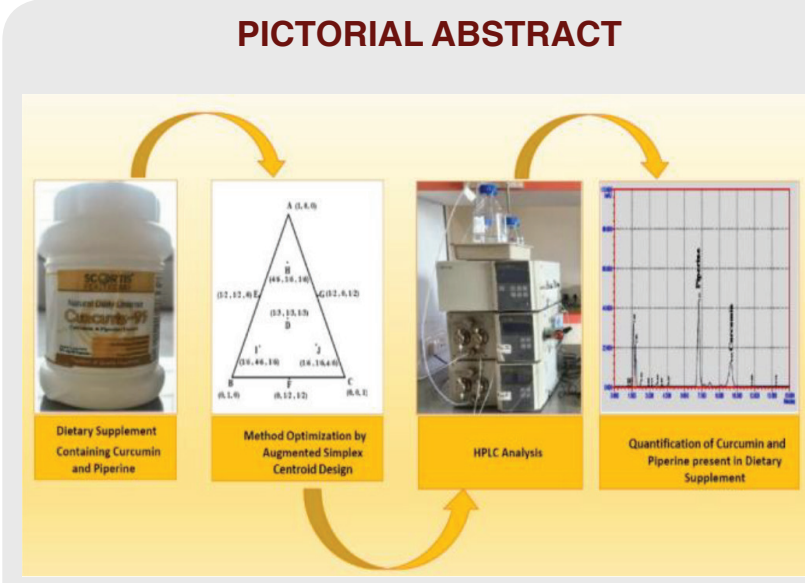

\section{SUMMARY}

Augmented simplex centroid design was used to develop HPLC method for quantification of curcumin and piperine in dietary supplement.

\section{About Authors}

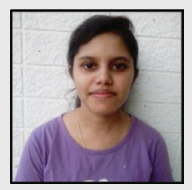

Ms. Jahnavi Naik has completed M. Pharm. in Quality Assurance from SSR College of Pharmacy, Silvassa, UT of Dadra and Nagar Haveli, India.

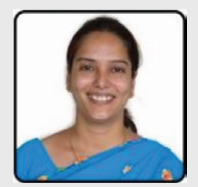

Dr. Sonal Desai is currently working as Associate Professor and Head, Department of Quality Assurance, SSR College of Pharmacy, Silvassa, UT of Dadra and Nagar Haveli, India.

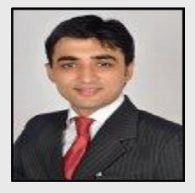

Dr. Vinodkumar Ramani is currently working as Assistant Professor, Department of Pharmaceutics, Bhagwan Mahavir College of Pharmacy, Surat, Gujarat, India.

Cite this article: Naik J, Desai S, Ramani V. Application of Augmented Simplex Centroid Design for Optimization of HPLC Mobile Phase for Estimation of Curcumin and Piperine. Indian J of Pharmaceutical Education and Research. 2021;55(4):1164-72. 